REVIEW

\title{
The location of constitutional neurofibromatosis 2 (NF2) splice site mutations is associated with the severity of NF2
}

\author{
M E Baser, L Kuramoto, R Woods, H Joe, J M Friedman, A J Wallace, R T Ramsden, S Olschwang, \\ E Bijlsma, M Kalamarides, L Papi, R Kato, J Carroll, C Lázaro, F Joncourt, D M Parry, G A Rouleau, \\ D G R Evans
}

J Med Genet 2005;42:540-546. doi: 10.1136/jimg.2004.029504

Neurofibromatosis 2 (NF2) patients with constitutional splice site NF2 mutations have greater variability in disease severity than NF2 patients with other types of mutations; the cause of this variability is unknown. We evaluated genotype-phenotype correlations, with particular focus on the location of splice site mutations, using mutation and clinical information on 831 patients from 528 NF2 families with identified constitutional NF2 mutations. The clinical characteristics examined were age at onset of symptoms of NF2 and number of intracranial meningiomas, which are the primary indices of the severity of NF2. Two regression models were used to analyse genotype-phenotype correlations. People with splice site mutations in exons 1-5 had more severe disease than those with splice site mutations in exons 11-15. This result is compatible with studies showing that exons 2 and 3 are required for selfassociation of the amino terminal of the NF2 protein in vitro, and that deletions of exons 2 and 3 in transgenic and knockout mouse models of NF2 cause a high prevalence of Schwann cell derived tumours.

See end of article for authors' affiliations

Correspondence to: Dr Michael E Baser, 10622 Kinnard Ave, \#203, Los Angeles, CA 90024; michael.baser@verizon. net

Revised version received 14 December 2004 Accepted for publication 15 December 2004
N eurofibromatosis 2 (NF2) is a rare autosomal dominant disease that is caused by nactivating mutations of the NF2 tumour suppressor gene. ${ }^{12}$ The NF2 gene has 17 exons and codes for a protein (termed merlin or schwannomin) that links the cytoskeleton to the cell membrane. The protein has 595 amino acids with three functional domains: an amino terminal domain, an $\alpha$ helical domain, and a carboxy terminal domain. NF2 codons 1-302 (exons 1-9) correspond to the predicted amino terminal domain, codons 303-478 (exons 10-13) to the $\alpha$ helical domain, and codons 479-595 (exons 14-17) to the carboxy terminal domain. Pathogenic NF2 mutations have not been found in exons 16 or 17 .

Clinically, NF2 is characterised by nervous system tumours and ocular abnormalities. ${ }^{3-5}$ Vestibular schwannomas, usually bilateral, occur in more than $90 \%$ of adult patients and intracranial meningiomas occur in about 50\% of patients. Mild and severe disease often can be defined by the age at onset of symptoms of NF2 and the number of cerebral tumours other than vestibular schwannomas..$^{5-7}$ In general, constitu- tional nonsense and frameshift NF2 mutations are associated with severe disease, and missense mutations and somatic mosaicism are associated with mild disease..$^{-14}$ In contrast, patients with constitutional splice site NF2 mutations have highly variable disease severity. ${ }^{15}$

The cause of the high phenotypic variability in NF2 patients with splice site mutations is not known. One hypothesis concerns the location of NF2 splice site mutations, specifically, that mutations in the carboxy terminal domain are associated with less severe disease than mutations in the amino terminal domain or $\alpha$ helical domain. Meningiomas occur in half of NF2 patients, but Kluwe et al ${ }^{15}$ reported that meningiomas were absent in 13 NF2 patients with constitutional splice site mutations in exons 14 or 15 (for conciseness, the location of splice site mutations is given by the closest exon). Somatic NF2 mutations are also common in sporadic meningiomas, but Wellenreuther et $a l^{16}$ did not find NF2 mutations of any type in exons 14 or 15 in 41 sporadic meningiomas.

In previous studies, we used the population based United Kingdom NF2 registry to demonstrate that there were genotype-phenotype correlations for individual types of NF2 related abnormalities. ${ }^{717}$ In this study, we used an international NF2 mutation database to further examine genotype-phenotype correlations in NF2, with particular focus on the location of constitutional NF2 splice site mutations. We found that splice site mutations in exons 1-5 were associated with more severe disease than splice site mutations in exons $11-15$, as indicated by younger onset of symptoms of NF2 and more intracranial meningiomas.

\section{METHODS \\ Patient data}

We compiled an international database from all published studies of NF2 mutations and related clinical data, the United Kingdom NF2 registry, and unpublished data from investigators. The database has the advantage of a very large sample size, although clinical data vary in completeness. Currently, the database has information on 1112 patients from 738 NF2 families with identified constitutional NF2 mutations. The database is described in the Human Gene Mutation Database ${ }^{18}$ and additional information is available from MEB.

People were eligible for this study if they had an identified constitutional NF2 mutation and information on the age at onset of symptoms of 
NF2, or the number of intracranial meningiomas, or both (subsequently, age at onset of symptoms refers to symptoms of NF2 and age at diagnosis refers to diagnosis of NF2). Age at onset of symptoms and number of intracranial meningiomas are the primary clinical indices of the severity of NF2. ${ }^{5-7}$ The analyses excluded people with rare types of NF2 mutations (in-frame deletions or insertions, large insertions, or chromosomal translocations) and somatic mosaics with mutations other than nonsense or frameshift mutations. A total of 831 patients from 528 NF2 families (409 people with new mutations and 422 inherited cases) met these criteria and were included in the study.

\section{Statistical methods}

Cross sectional associations of the type of constitutional NF2 mutation with the age at onset of symptoms and the number of meningiomas were assessed by regression models. The models were chosen on the basis of the nature of the dependent variable. A multivariate normal model with right censoring was used to model the association of the type of constitutional NF2 mutation with the age at onset of symptoms. For asymptomatic patients, the age at onset of symptoms was right censored at the older of two other age variables (age at diagnosis and age at last examination or death). A gamma mixture of negative binomials model was used to evaluate the association of the type of constitutional NF2 mutation with the number of intracranial meningiomas because the count distribution of meningiomas was heavily right skewed. Models were fit by maximum likelihood estimated using the quasi-Newton method. Computations were done using C programs developed at the Department of Statistics, University of British Columbia (available from HJ).

Each model had an exchangeable correlation structure within families that permitted assessment of intrafamilial effects beyond those due to the type of constitutional NF2 mutation. The other covariates in each model were gender and inheritance (new mutation or inherited case). In the meningioma model, the age at last examination or at death (or the age at diagnosis if this information was missing) was a covariate because the penetrance of NF2 associated meningiomas increases with age. ${ }^{7}$

The type of mutation variable was classified categorically as seven binary variables. These variables were indicators of somatic mosaicism (defined at the molecular level), splice site mutations (subdivided by location), missense mutations, large deletions, and patients with full constitutional nonsense or frameshift mutations. The latter group of patients, who typically have severe disease, was the reference group for statistical comparisons.

For the purpose of the analysis, we divided the location of splice site mutations into three groups using two different methods. There were 128 families with splice site mutations, but these mutations were distributed unevenly among the 15 NF2 exons in which pathogenic mutations have been reported. There was only one mutation in exon 1 and only two mutations each in exons 9 and 10. There are several possible ways to group the exons, and two different approaches were used in the analysis. In the first analysis, splice site mutations were divided according to the predicted merlin functional domains (exons 1-9, 10-13, and 14-15). In the second analysis, splice site mutations were divided in three equal groups by exon number without a priori reference to functional domains (exons 1-5, 6-10, and 11-15).

Genotype-phenotype correlations were evaluated using the model based dependent variables and their 95\% confidence intervals (CI). CIs that excluded zero were considered to be statistically significant. CIs were calculated in two ways: for different types of mutations relative to the reference group (that is, with splice site mutations analysed as a single class), and between the three NF2 regions of splice site mutations. To evaluate differences between people with splice site mutations in the three NF2 regions, the 95\% CI of the difference between the model coefficients for the exon categories was calculated (for example, the difference in the age at onset of symptoms between people with splice site mutations in exons $1-5 \vee 6-10$, exons $1-5 \vee 11-15$, and exons $6-10<11-15)$.

Kaplan-Meier analysis was used to compare survival in people with splice site mutations in different regions of the NF2 gene. Only patients from the United Kingdom NF2 registry were used in the survival analysis because the registry has complete ascertainment of survival. The United Kingdom NF2 registry has 94 NF2 patients from 51 families with splice site mutations. To account for the positive association within families, the $\mathrm{p}$ value was based on the null permutation distribution of the log rank statistic, with permutation of families. Under the null hypothesis of equal survival distribution in the two groups, families can be permuted to each of the two groups (while keeping the same number of families in each group as in the original data), and the log rank statistic can be computed for each permutation.

\section{RESULTS}

The characteristics of the study population are presented in table 1 . As in previously published studies that were included in the international NF2 mutation database, somatic mosaics and people with non-truncating mutations had milder disease than people with full constitutional nonsense or frameshift mutations (the reference group). Somatic mosaics and people with splice site mutations, missense mutations, or large deletions were older at onset of symptoms and at diagnosis than the reference group. The prevalence of meningiomas was lower in people with splice site mutations, missense mutations, or large deletions than in the reference group.

The genotype-phenotype correlations are presented in tables 2 and 3. These tables have the observed and model based maximum likelihood estimates for average age at onset of symptoms (table 2) and average number of meningiomas (table 3). The model based estimate of the average age at onset of symptoms was significantly higher in somatic mosaics (29 years) and in people with missense mutations ( 31 years) or large deletions (23 years) than in the reference group ( 16 years) (table 2 ). The model based estimate of the average number of meningiomas was significantly lower in people with missense mutations (0.4) or large deletions (0.8) than in the reference group (1.7) (table 3). When splice site mutations were analysed as a single class, people with splice site mutations were significantly older at onset of symptoms and had significantly fewer meningiomas than the reference group.

The genotype-phenotype correlations for the location of splice site mutations are of particular interest. The results for the two groupings were similar for age at onset of symptoms, although the model based on grouping of exons by functional domains produced mean ages of onset that were slightly closer to the observed averages (table 2). People with splice site mutations in exons $1-9$ were significantly younger at onset of symptoms than people with mutations in exons 1415. Similarly, people with NF2 splice site mutations in exons 1-5 or 6-10 were significantly younger at onset of symptoms than people with splice site mutations in exons $11-15$.

For number of meningiomas, the grouping based on equal number of exons provided more precise genotype-phenotype correlations within the predicted amino terminal domain. People with splice site mutations in exons $1-9$ had significantly more meningiomas than people with mutations in exons 14-15, but people with mutations in exons $1-5$ had 
Table 1 Characteristics of 831 people with NF2 by type of NF2 mutation

\begin{tabular}{|c|c|c|c|c|c|}
\hline \multirow[b]{3}{*}{ Characteristic } & \multicolumn{5}{|c|}{ Type of NF2 mutation } \\
\hline & \multicolumn{2}{|c|}{ Nonsense or frameshift } & \multirow[b]{2}{*}{ Splice site } & \multirow[b]{2}{*}{ Missense } & \multirow[b]{2}{*}{ Large deletion } \\
\hline & Classical* $^{*}$ & Somatic mosaic & & & \\
\hline $\begin{array}{l}\text { Number of people/families } \\
\text { Inheritance (\%) }\end{array}$ & $340 / 272$ & 40 & $263 / 128$ & $73 / 25$ & $115 / 63$ \\
\hline New mutations & 60 & 100 & 32 & 15 & 40 \\
\hline Inherited cases & 40 & 0 & 68 & 85 & 60 \\
\hline \multicolumn{6}{|l|}{ Gender (\%) } \\
\hline Female & 45 & 50 & 50 & 44 & 50 \\
\hline Male & 55 & 50 & 50 & 56 & 50 \\
\hline \multicolumn{6}{|l|}{ Age, mean (SD) (years) } \\
\hline Onset of symptoms of NF2† & $16(10)$ & $29(11)$ & $23(12)$ & $29(14)$ & $24(11)$ \\
\hline Diagnosis of NF2 & $22(12)$ & 39 (12) & $29(15)$ & $36(19)$ & $28(14)$ \\
\hline \multicolumn{6}{|l|}{ Vestibular schwannoma (\%) } \\
\hline None & 7 & 11 & 13 & 7 & 5 \\
\hline Unilateral & 4 & 13 & 8 & 7 & 6 \\
\hline Bilateral & 89 & 76 & 79 & 86 & 89 \\
\hline \multicolumn{6}{|l|}{ Intracranial meningioma (\%) } \\
\hline Absent & 31 & 41 & 60 & 71 & 69 \\
\hline Present & 69 & 59 & 40 & 29 & 31 \\
\hline
\end{tabular}

significantly more meningiomas than people with mutations in exons $6-10$ or 11-15. Overall, when the results for age at onset of symptoms and number of meningiomas are taken together, people with splice site mutations in exons $1-5$ have more severe disease than people with mutations in exons 1115.

Other covariates contributed significantly to the models after adjustment for the type of constitutional NF2 mutation. There was a weak but significant intrafamilial correlation for age at onset of symptoms $(0.21,95 \%$ CI 0.13 to 0.30$)$, but neither age, inheritance, nor gender were significant explanatory variables in these models. Similarly, there was a weak but significant intrafamilial correlation for number of meningiomas $(0.18,95 \%$ CI 0.06 to 0.30$)$. Inherited cases had significantly fewer meningiomas than people with new mutations (0.5-fold, $95 \%$ CI 0.2 - to 0.8 -fold). The number of meningiomas increased slightly but not significantly with increasing age, and gender did not significantly influence the number of meningiomas.

For the Kaplan-Meier survival analysis, the location of splice site mutations was dichotomised into exons 1-5 or 615 because people with splice site mutations in exons $1-5$ had the most severe disease. There were too few people with splice site mutations in exons $14-15$ to support a mortality

Table 2 Genotype-phenotype correlations for the age at onset of symptoms of NF2

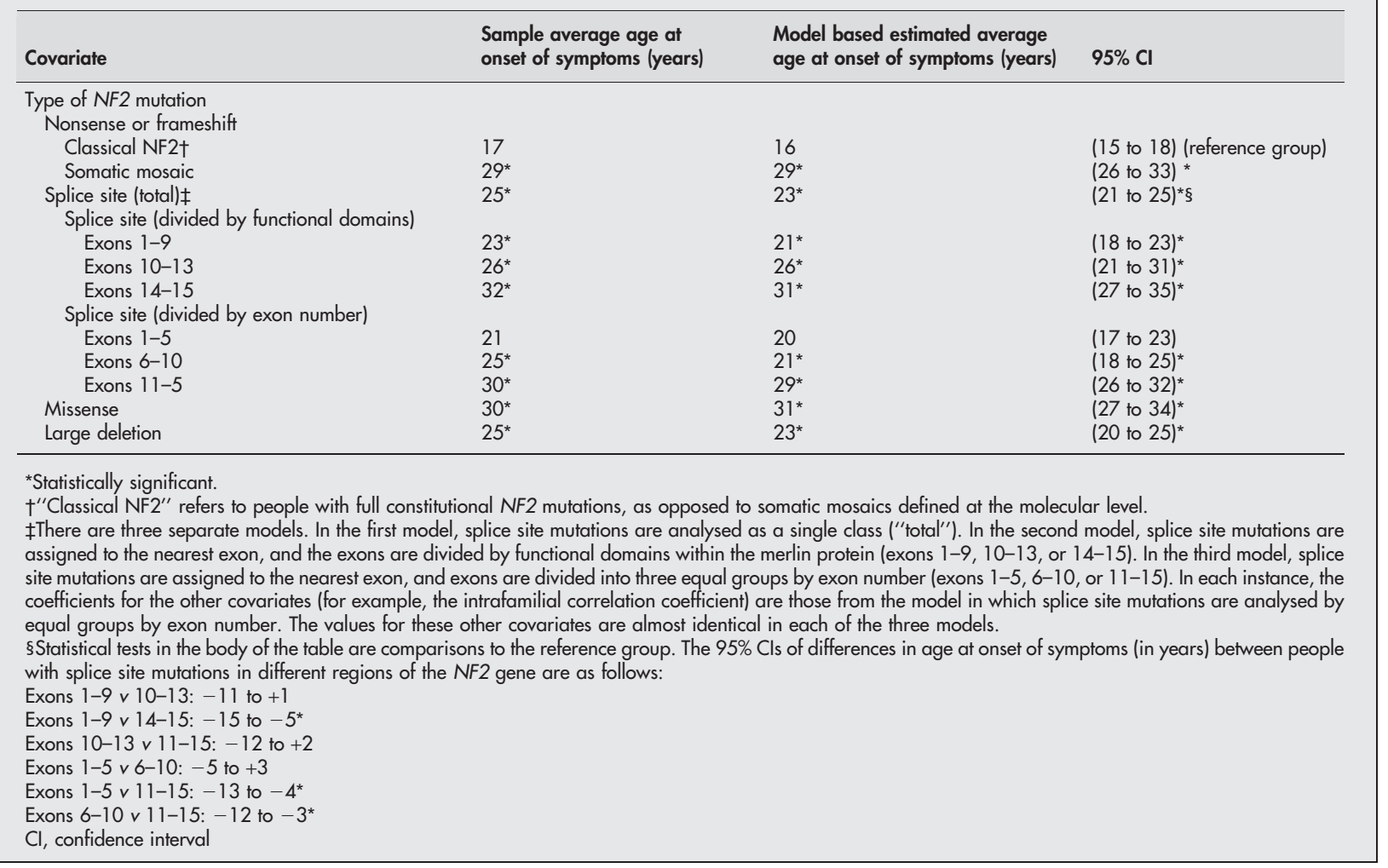


Table 3 Genotype-phenotype correlations for the number of intracranial meningiomas

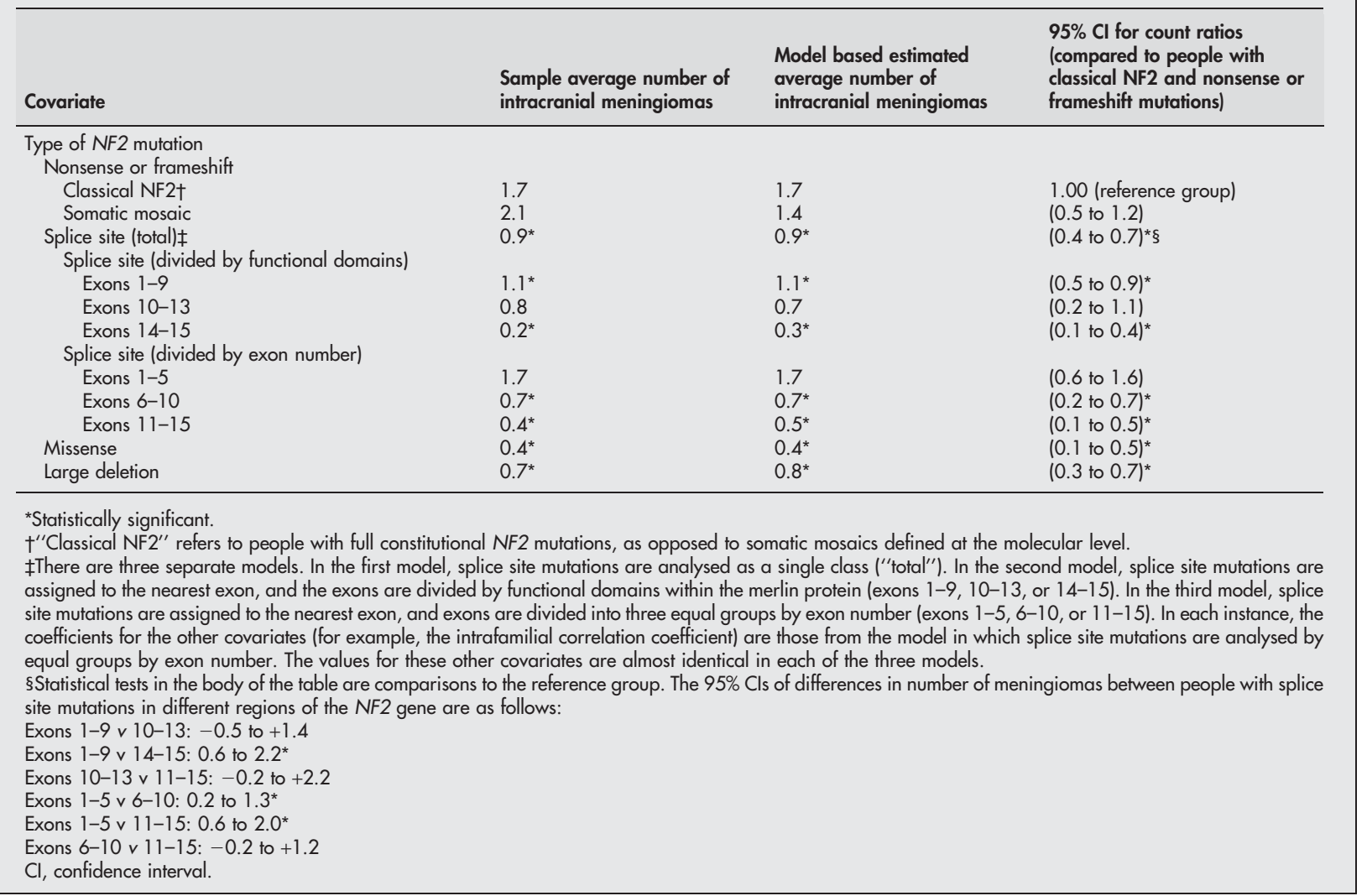

analysis using that category. As seen in fig 1, people with splice site mutations in exons $1-5$ had significantly lower survival than people with splice site mutations in exons 6-15 (permutation distribution $\mathrm{p}$ value for the log rank statistic $=0.037)$.

\section{DISCUSSION}

Almost all previous studies of genotype-phenotype correlations in NF2 have been based on relatively few patients due to the rarity of the disease. ${ }^{19}$ Larger studies with detailed

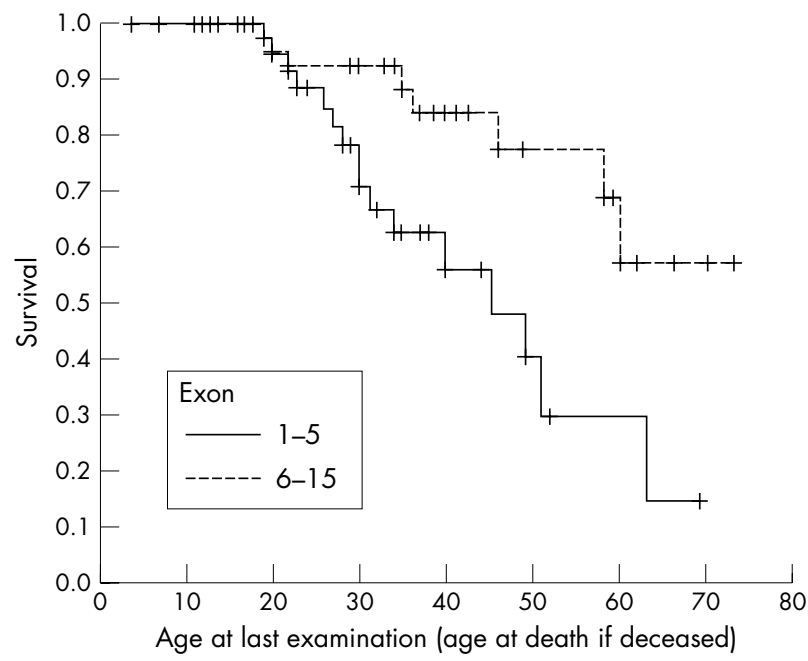

Figure 1 Kaplan-Meier survival analysis of NF2 patients with splice site mutations from the United Kingdom NF2 registry: patients with mutations in exons $1-5$ or exons $6-15$ (permutation distribution $p$ value for the log rank statistic $=0.037$ ) clinical data are needed to evaluate specific genotypephenotype correlations, such as correlations for individual types of NF2 associated abnormalities and correlations for the location of a single type of mutation within the NF2 gene. Recently, we evaluated genotype-phenotype correlations for individual types of $\mathrm{NF} 2$ associated abnormalities using the population based United Kingdom NF2 registry, which has information on 560 people with NF2. We found that there were genotype-phenotype correlations for intracranial meningiomas, spinal tumours, peripheral nerve tumours, and cataracts. ${ }^{7}{ }^{17}$ Genotype-phenotype correlations for specific types of abnormalities have been found in other diseases that are caused by mutations in other tumour suppressor genes, notably $A P C, V H L$, and $N F 1$.

Yet even the United Kingdom NF2 registry is not large enough to evaluate genotype-phenotype correlations for the location of a single type of mutation within the NF2 gene. In this study, we used an international NF2 mutation database to extend NF2 genotype-phenotype correlations to the location of splice site mutations. Our findings are analogous to those that have been observed for the location of APC mutations and the number of colorectal adenomas, ${ }^{20-23}$ the occurrence of congenital hypertrophy of the retinal pigment epithelium, ${ }^{24-26}$ the occurrence of desmoid tumours, ${ }^{25} 26$ and the age at onset of colon cancer. ${ }^{27}$ However, our findings differ from the genotype-phenotype correlations in APC because there is not a genotype-phenotype correlation for the location of all types of mutations within the NF2 gene. The location of nonsense and frameshift NF2 mutations, which occur in $56 \%$ of NF2 families, ${ }^{18}$ is not significantly associated with the age at onset of symptoms of NF2 or the number of meningiomas (data not shown).

Genotype-phenotype correlations in NF2 have been studied experimentally. Naturally occurring single-base pair substitutions (missense mutations and nonsense mutations) have 
been used to identify the location of amino acid residues that are critical for the tumour suppressor function of merlin. Missense mutations produce merlin that is defective in negative growth regulation, while nonsense mutations do not produce stable merlin. ${ }^{28}$ Missense mutations also produce merlin with reduced but not absent binding to $\beta I I$ spectrin. ${ }^{29}{ }^{30}$ In this study, we confirmed that missense mutations are usually associated with mild NF2.

Missense mutations occur in only $5 \%$ of NF2 families, ${ }^{18}$ and the number of currently available patients is insufficient to test the association of the location of missense mutations with phenotype. Splice site NF2 mutations are more common, occurring in $25 \%$ of NF2 families. The effects of splice site mutations are more complex than those of missense mutations and may include exon skipping or the use of cryptic splice sites, leading to frameshifts to stop codons, the production of various peptides, or leaky expression. In general, though, exon skipping occurs more frequently than the use of cryptic splice sites. ${ }^{31}$ Therefore, it may be possible to relate the results of the present study to experimental studies in which specific NF2 exons were deleted.

Gutmann and colleagues proposed a model of "closed" and "open" merlin conformations, in which the closed conformation is active as a tumour suppressor. In this model, merlin forms two intramolecular associations, one within the amino terminal domain and another between the amino terminal domain and the carboxy terminal domain..$^{28} 32{ }^{33}$ The $\alpha$ helical domain may serve as a hinge to bring the amino terminal domain and the carboxy terminal domain together. The amino terminal domain self-association stabilises the interaction between the amino terminal domain and the carboxy terminal domain.

The relevance of this model to the results of the present study is that NF2 exons 2 and 3 are required for selfassociation of the amino terminal domain in vitro, and this self-association is necessary for merlin to function as a tumour suppressor. ${ }^{28}$ In transgenic and knockout mouse models of NF2, deletions of exons 2 and 3 cause a high prevalence of Schwann cell hyperplasia and Schwann cell derived tumours, in contrast to deletions of exons in the predicted carboxy terminal domain. ${ }^{34}{ }^{35}$ In the present study, the association of splice site mutations in exons 1-9 (and especially exons 1-5) with severe NF2 is compatible with these experimental studies.

Since the genotype-phenotype correlations for the location of splice site mutations imply that the location of deletions in the NF2 gene is associated with disease severity, we evaluated genotype-phenotype correlations between the location of intragenic large deletions and the age at onset of symptoms. Forty eight people from 24 families had intragenic large deletions that could be localised to either exons $1-9$ or exons 10-15 and had information on age at onset of symptoms. We used the multivariate normal model with exchangeable dependence and right censoring as described in the Methods section, to evaluate genotype-phenotype correlations. The model based estimated average age at onset of symptoms for people with intragenic large deletions in exons 1-9 was 19 years, compared to 30 years in people with intragenic large deletions in exons $10-15(p=0.02)$. This is consistent with the genotype-phenotype correlation for the location of splice site mutations.

Another implication of our results is that $3^{\prime}$ NF2 splice site mutations can produce partially functional merlin. There have been many immunohistochemical studies of merlin expression in vestibular schwannomas and meningiomas, but most of the studied tumours have been sporadic rather than occurring in NF2 patients, and specific NF2 mutations usually have not been reported. ${ }^{36-41}$ The strongest direct evidence that splice site NF2 mutations can produce partially functional merlin comes from a well characterised NF2 family with a very mild phenotype and a constitutional $1737+3 \mathrm{~A} \rightarrow \mathrm{T}$ splice donor site mutation. Exon 15 was skipped in fibroblasts and tumour cells from affected family members, and merlin was expressed with the carboxy terminus of isoform III. ${ }^{42} 43$

Kluwe et $a l^{15}$ reported that patients with constitutional splice site NF2 mutations in exons 14-15 did not have meningiomas, and hypothesised that exons 14 and 15 had less of a role in tumour suppression of meningiomas than in suppression of other NF2 related tumours. The present study confirms that there are fewer meningiomas in NF2 patients with splice site mutations in exons 14-15. However, our results are more consistent with an effect on overall disease severity rather than on meningioma formation alone because patients with splice site mutations in 3' exons also had older onset of symptoms. In addition, the effect on number of meningiomas does not appear to be limited to exons 14-15. People with splice site mutations in exon 6-10 and 11-15 each had significantly fewer meningiomas than people with splice site mutations in exons 1-5.

Age at onset of symptoms and number of meningiomas provide complementary information for genotype-phenotype correlations in NF2 because presenting symptoms in NF2 usually are not related to meningiomas. The most common presenting symptoms of NF2 are hearing loss, tinnitus, vertigo, or imbalance, which are usually caused by vestibular schwannomas..$^{3-5}$ Seizures or headaches, the usual symptoms of meningiomas, are the presenting symptoms in only $6-8 \%$ of symptomatic NF2 patients. ${ }^{3-5}$

Age at onset of symptoms of NF2 and age at diagnosis of NF2 are strong predictors of the risk of mortality in NF2. ${ }^{44}$ The association between the location of splice site mutations and survival in the present study probably reflects the differences in age at onset of symptoms in people with splice site mutations in different regions of the NF2 gene. When the location of splice site mutations and age at onset of symptoms are both included as covariates in a Cox regression model, mutation location is not an independent predictor of mortality (data not shown).

We found that, in general, NF2 large deletions were associated with mild clinical manifestations of NF2 (in the sub-group analysis, the position of intragenic large deletions within the NF2 gene was associated with the age at onset of symptoms). The cause of the association of NF2 large deletions with mild disease is unknown. Constitutional NF2 large deletions are common, occurring in $21-32 \%$ of NF2 families, ${ }^{45}{ }^{46}$ but conventional mutation screening techniques such as single strand conformation polymorphism analysis do not detect heterozygous large deletions. There have been few published data on genotype-phenotype correlations for NF2 large deletions, ${ }^{12}{ }^{45-47}$ but our findings are consistent with these earlier observations.

Bruder et $a l^{48}$ hypothesised that there was a modifier gene for NF2 located telomeric to NF2 on chromosome 22. These investigators then used microarray-comparative genomic hybridisation in a series of NF2 patients with large deletions and demonstrated that the deletions in people with moderate or severe NF2 often extended beyond the NF2 locus, while the deletions in people with mild NF2 only affected the NF2 locus itself. ${ }^{46}$ When NF2 large deletions in the international database are classified as either whole gene deletions or deletions that involve part of the NF2 gene, people with these two types of large deletions do not have significantly different mean ages at onset of symptoms or numbers of intracranial meningiomas (data not shown). However, this broad categorisation of the size of NF2 large deletions may not be sufficiently precise to identify the phenotypic effects of putative modifier genes near the NF2 locus. 
Somatic mosaicism occurs in an estimated $25-30 \%$ of NF2 patients with new mutations..$^{49}{ }^{50}$ Our data suggest that there is ascertainment bias in the identification of somatic mosaics. In the international database, 65 (79\%) of 82 known mosaics have nonsense mutations, frameshift mutations, or indels, while only 241 (57\%) of 420 people with new mutations and full constitutional mutations have these types of mutations (Fisher's exact test, $\mathrm{p}<0.001$ ). Full constitutional nonsense mutations and frameshift mutations usually cause severe NF2. Somatic mosaics with nonsense or frameshift mutations may be more likely to be diagnosed because their phenotype, although attenuated by mosaicism, is still severe enough to be classified as NF2, while mosaicism in people with other types of mutations may produce a phenotype that is so mild that it escapes medical attention or fails to meet the standard clinical diagnostic criteria for NF2. ${ }^{51}$

After accounting for genotype-phenotype correlations in regression models, there were weak but significant intrafamilial correlations for the age at onset of symptoms and the number of meningiomas. We previously demonstrated these correlations in a subset of patients from the present study. ${ }^{52}$ Intrafamilial correlations may reflect differences in the phenotype of individual NF2 alleles that comprise a mutation type, or these correlations might be evidence of modifying genes.

The finding that inherited cases had fewer meningiomas than people with new mutations may be due to reproductive selection. As seen in table 1, the proportion of inherited cases is higher in people with splice site mutations, missense mutations, or large deletions than in people with full constitutional nonsense or frameshift mutations. Full constitutional nonsense or frameshift mutations usually cause severe NF2, and these patients are less likely to reproduce because they often die in the third or fourth decade of life and are typically debilitated for a lengthy time beforehand.

There are genotype-phenotype correlations for many disease manifestations of NF2, but there can still be considerable intra-familial phenotypic variability. Vestibular schwannoma growth rates can vary markedly among multiple affected relatives of similar ages in the same NF2 family. ${ }^{53}$ Specific disease manifestations and disease course also may differ between monozygotic twins with NF2. ${ }^{54}$ These observations indicate that the phenotype of NF2 is probably influenced by gene-environment interactions or stochastic factors, in addition to the effects of the mutant NF2 allele and other familial (and presumably genetic) factors demonstrated in this study. With further research, it may be possible to assess the contribution of all of these factors to the phenotype of NF2. For application in the clinical setting, the age at onset of symptoms of NF2 or age at diagnosis of NF2 are the strongest predictors of the course of the disease. ${ }^{64}$

\section{Authors' affiliations}

M E Baser, 10622 Kinnard Ave, \#203, Los Angeles, CA, USA

L Kuramoto, R Woods, H Joe, Department of Statistics, University of British Columbia, Vancouver, BC, Canada

J M Friedman, Department of Medical Genetics, University of British Columbia, Vancouver, BC, Canada

A J Wallace, D G R Evans, University Department of Medical Genetics, St Mary's Hospital, Manchester, UK

R T Ramsden, Department of Otolaryngology, Manchester Royal Infirmary, Manchester, UK

S Olschwang, INSERM U434, Fondation Jean-Dausset-CEPH, Paris, France

E Bijlsma, Department of Clinical Genetics, Leiden University Medical Center, Leiden, The Netherlands

M Kalamarides, Department of Neurosurgery, University Hospital Beaujon, Clichy, France

L Papi, Department of Clinical Physiopathology, University of Florence, Florence, Italy
R Kato, Department of Pediatrics, Higashisaitama National Hospital, Saitama, Japan

J Carroll, Division of Molecular Pathology, Institute of Medical and Veterinary Science, Adelaide, Australia

C Lázaro, Centre de Genètica Mèdica i Molecular - I.R.O., L'Hospitalet de Llobregat, Barcelona, Spain

F Joncourt, Division of Human Genetics, Children's University Hospital, Berne, Switzerland

D M Parry, Genetic Epidemiology Branch, National Cancer Institute, Bethesda, MD, USA

G A Rouleau, Department of Neurology, McGill University, Montreal, QC, Canada

Supported in part by the FBT Foundation and US Army grant U.S.A.R.M.C. NF990038. CL was partially supported by grants from the Fondo de Investigaciones Sanitarias (FISO1/1475), the Ministerio de Educación y Ciencia (SAF2002-00573), the Institut Catala de la Salut (ISIII C03/07), and 2001SGR00399 from Generalitat de Catalunya, Spain.

Competing interests: none declared

\section{REFERENCES}

1 Trofatter JA, MacCollin MM, Rutter JL, Murrell JR, Duyao MP, Parry DM, Eldridge R, Kley N, Menon AG, Pulaski K, Haase VH, Ambrose CM, Munroe D, Bove C, Haines JL, Martuza RL, MacDonald ME, Seizinger BR, Short MP, Buckler AJ, Gusella JF. A novel moesin-, ezrin-, radixin-like gene is a candidate for the neurofibromatosis 2 tumor suppressor. Cell 1993;72:791-800.

2 Rouleau GA, Mérel $P$, Lutchman $M$, Sanson M, Zucman J, Marineau $C$, Hoang-Xuan K, Demczuk S, Desmaze C, Plougstel B, Pulst SM, Lenoir G, Biilsma E, Fashold R, Dumanski J, de Jong P, Parry D, Eldridge R, Aurias A, Delattre $O$, Thomas $G$. Alteration in a new gene encoding a putative membrane-organizing protein causes neurofibromatosis type 2. Nature 1993;363:515-21.

3 Evans DGR, Huson SM, Donnai D, Neary W, Blair V, Newton V, Harris R. A clinical study of type 2 neurofibromatosis. Q J Med 1992;84:603-18.

4 Mautner VF, Lindenau M, Baser ME, Hazim W, Tatagiba M, Haase W, Samii M, Wais R, Pulst SM. The neuroimaging and clinical spectrum of neurofibromatosis 2. Neurosurgery 1996;38:880-5.

5 Parry DM, Eldridge R, Kaiser-Kupfer MI, Bouzas EA, Pikus A, Patronas N. Neurofibromatosis 2 (NF2): clinical characteristics of 63 affected individuals and clinical evidence for heterogeneity. Am J Med Genet 1994;52:450-61.

6 Baser ME, Friedman JM, Aeschliman D, Joe H, Wallace AJ, Ramsden RT, Evans DGR. Predictors of the risk of mortality in neurofibromatosis 2 . Am J Hum Genet 2002;71:715-23.

7 Baser ME, Kuramoto L, Joe H, Friedman JM, Wallace AJ, Gillespie JE, Ramsden RT, Evans DGR. Genotype-phenotype correlations for nervous system tumors in neurofibromatosis 2: a population-based study. Am J Hum Genet 2004;75:231-9.

8 Mérel P, Hoang-Xuan K, Sanson M, Bijlsma E, Rouleau G, Laurent-Puig P, Pulst S, Baser M, Lenoir G, Sterkers JM, Philippon J, Resche F, Mautner VF, Fischer G, Hulsebos T, Aurias A, Delattre O, Thomas G. Screening for germline mutations in the NF2 gene. Genes Chromosomes Cancer 1995; 12:117-27.

9 Parry DM, MacCollin MM, Kaiser-Kupfer MI, Pulaski K, Nicholson HS, Boleseta M, Eldridge R, Gusella JF. Germ-line mutations in the neurofibromatosis 2 gene: correlations with disease severity and retinal abnormalities. Am J Hum Genet 1996;59:529-39.

10 Ruttledge MH, Andermann AA, Phelan CM, Claudio JO, Han F-Y, Chretien N, Rangaratnam S, MacCollin M, Short P, Parry D, Michels V, Riccardi VM, Weksberg R, Kitamura K, Bradburn JM, Hall BD, Propping P, Rouleau GA. Type of mutation in the neurofibromatosis type 2 gene (NF2) frequently determines severity of disease. Am J Hum Genet 1996;59:331-42.

11 Kluwe L, Beyer S, Baser ME, Hazim W, Haase W, Fünsterer C, Mautner VF. Identification of NF2 germ-line mutations and comparison with NF2 phenotypes. Hum Genet 1996;98:534-8.

12 Evans DGR, Trueman L, Wallace A, Collins S, Strachan T. Genotype/ phenotype correlations in type 2 neurofibromatosis (NF2): evidence for more severe disease associated with truncating mutations. J Med Genet 1998;35:450-5.

13 Evans DGR, Wallace AJ, Wu CL, Trueman L, Ramsden RT, Strachan T. Somatic mosaicism: a common cause of classic disease in tumor-prone syndromes? Lessons from type 2 neurofibromatosis. Am J Hum Genet 1998;63:727-36.

14 Kluwe L, Mautner V-F. Mosaicism in sporadic neurofibromatosis 2 patients. Hum Mol Genet 1998;7:2051-5.

15 Kluwe L, MacCollin M, Tatagiba M, Thomas S, Hazim W, Haase W, Mautner VF. Phenotypic variability associated with 14 splice-site mutations in the NF2 gene. Am J Med Genet 1998;77:228-33.

16 Wellenreuther R, Kraus JA, Lenartz D, Menon AG, Schramm J, Louis DN, Ramesh V, Gusella JF, Wiestler OD, von Deimling A. Analysis of the neurofibromatosis 2 gene reveals molecular variants of meningioma. Am J Pathol 1995:146:827-32.

17 Baser ME, Kuramoto L, Joe H, Friedman JM, Wallace AJ, Ramsden RT, Evans DGR. Genotype-phenotype correlations for cataracts in neurofibromatosis 2. J Med Genet 2003;40:758-60. 
18 Baser ME. Neurofibromatosis 2 (NF2) mutation databases. Human Gene Mutation Database 2004. http://uwcmml 1 s.uwcm.ac.uk/uwcm/mg/nf2 (accessed 6 January 2005).

19 Evans DGR, Huson SM, Donnai D, Neary W, Blair V, Teare D, Newton V, Harris R. A genetic study of type 2 neurofibromatosis in the United Kingdom. I. Prevalence, mutation rate, fitness and confirmation of maternal transmission effect on severity. J Med Genet 1992;29:841-6.

20 Nagase H, Miyoshi Y, Horii A, Aoki T, Ogawa M, Utsunomiya J, Baba S, Sasazuki T, Nakamura Y. Correlation between the location of germ-line mutations in the APC gene and the number of colorectal polyps in familial adenomatous polyposis patients. Cancer Res 1992;52:4055-7.

21 Spirio L, Olschwang S, Groden J, Robertson M, Samowitz W, Joslyn G, Gelbert $L$, Thiveris A, Carlson $M$, Otterud B, Lynch $H$, Watson $P$, Lynch $P$, Laurent-Puig P, Burt R, Hughes JP, Thomas $G$, Leppert M, White R. Alleles of the APC gene: an attenuated form of familial polyposis. Cell 1993:75:951-7.

22 Soravia C, Berk T, Madlensky L, Mitri A, Cheng H, Gallinger S, Cohen Z, Bapat B. Genotype-phenotype correlations in attenuated adenomatous polyposis coli. Am J Hum Genet 1998;62:1290-301.

23 Su L-K, Barnes CJ, Yao W, Qi Y, Lynch PM, Steinback G. Inactivation of germline mutant $A P C$ alleles by attenuated somatic mutations: a molecular genetic mechanism for attenuated familial adenomatous polyposis. Am J Hum Genet 2000;67:582-90.

24 Olschwang S, Tiret A, Laurent-Puig P, Muleris M, Parc R, Thomas G. Restriction of ocular fundus lesions to a specific group of $A P C$ mutations in adenomatous polyposis coli patients. Cell 1993;75:959-68.

25 Caspari R, Olschwang S, Friedl W, Mandl M, Boisson C, Böker T, Augustin A, Kadmon M, Möslein G, Thomas G, Propping P. Familial adenomatous polyposis: desmoid tumours and lack of ophthalmic lesions (CHPRE) associated with APC mutations beyond codon 1444. Hum Mol Genet 1995;4:337-40.

26 Davies DR, Armstrong JG, Thakker N, Horner K, Sloan P, Dodd C, Guy SP Clancy T, Evans DGR. Severe Gardner's syndrome in families with mutations restricted to a specific region of the APC gene. Am J Hum Genet 1995;57:1151-8

27 Caspari R, Friedl W, Mandl M, Möslein G, Kadmon M, Knapp M, Jacobasch K-H, Ecker K-W, Kreißler-Haag D, Timmermanns G, Propping P. Familial adenomatous polyposis: mutation at codon 1309 and early onset of colon cancer. Lancet 1994:343:629-32.

28 Gutmann DH, Geist RT, Xu H-M, Kim JS, Saporito-Irwin S. Defects in neurofibromatosis 2 protein function can arise at multiple levels. Hum Mol Genet 1998;7:335-45.

29 Scoles DR, Huynh DP, Morcos PA, Coulsell ER, Robinson NGG, Tamanoi F Pulst DM. Neurofibromatosis 2 tumour suppressor schwannomin interacts with Bll-spectrin. Nat Genet 1998; 18:354-9.

30 Scoles DR, Chen M, Pulst SM. Effects of Nf2 missense mutations on schwannomin interactions. Biochem Biophys Res Commun 2002;290:366-74.

31 Krawczak M, Reiss J, Cooper DN. The mutational spectrum of single basepair substitutions in mRNA splice junctions of human genes: causes and consequences. Hum Genet 1992;90:41-54.

32 Gutmann DH, Haipek CA, Lu KH. Neurofibromatosis 2 tumor suppressor protein, merlin, forms two functionally important intramolecular associations. J Neurosci Res 1999;58:706-16.

33 Gutmann DH, Hirbe AC, Haipek CA. Functional analysis of neurofibromatosis 2 (NF2) missense mutations. Hum Mol Genet 2001;10:1519-29.

34 Giovannini $M$, Robanus-Maandag E, Niwa-Kawakita $M$, van der Valk $M$ Woodruff JM, Goutebroze L, Merel P, Berns A, Thomas G. Schwann cell hyperplasia and tumors in transgenic mice expressing a natural occurring mutant NF2 protein. Genes Dev 1999;13:978-86

35 Giovannini M, Robanus-Maandag E, van $\operatorname{der}$ Valk M, Niwa-Kawakita M, Abramowski V, Goutebroze L, Woodruff JM, Berns A, Thomas G. Conditional biallelic Nf2 mutation in the mouse promotes manifestations of human neurofibromatosis 2. Genes Dev 2000;14:1617-30.

36 Sainz J, Huynh DP, Figueroa K, Ragge NK, Baser ME, Pulst SM. Mutations of the neurofibromatosis type 2 gene and lack of the gene product in vestibular schwannomas. Hum Mol Genet 1994;3:885-91.
37 Huynh DP, Mautner V, Baser ME, Stavrou D, Pulst SM. Immunohistochemical detection of schwannomin and neurofibromin in vestibular schwannomas, ependymomas and meningiomas. J Neuropathol Exp Neurol 1997:56:382-90.

38 Gutmann DH, Giordano MJ, Fishback AS, Guha A. Loss of merlin expression in sporadic meningiomas, ependymomas and schwannomas. Neurology 1997;49:267-70.

39 Hitotsumatsu T, Iwaki T, Kitamoto T, Mizoguchi M, Suzuki SO, Hamada Y, Fukui $M$, Tateishi J. Expression of neurofibromatosis 2 protein in human brain tumors: an immunohistochemical study. Acta Neuropathol 1997.93:225-32.

40 Stemmer-Rachamimov AO, Xu L, Gonzalez-Agosti C, Burwick JA, Pinney D, Beauchamp R, Jacoby LB, Gusella JF, Ramesh V, Louis DN. Universal absence of merlin, but not other ERM family members, in schwannomas. Am J Pathol 1997;151:1649-54.

41 den Bakker MA, Tilbourg AAG, Kors JM, Zwarthoff EC. Truncated NF2 proteins are not detected in meningiomas and schwannomas. Neuropathology $2001 ; 21: 168-73$.

42 Sainio M, Strachan T, Blomstedt G, Salonen O, Setala K, Palotie A, Palo J, Pyykko I, Peltonen L, Jääskeläinen J. Presymptomatic DNA and MRI diagnosis of neurofibromatosis 2 with mild clinical course in an extended pedigree. Neurology 1995;45:1314-22.

43 Sainio M, Jääskeläinen J, Pihlaja H, Carpén O. Mild familial neurofibromatosis 2 associates with expression of merlin with altered $\mathrm{COOH}$ terminus. Neurology 2000:54:1132-8.

44 Otsuka G, Saito K, Nagatani T, Yoshida J. Age at symptom onset and longterm survival in patients with neurofibromatosis type 2. J Neurosurg 2003;99:480-3.

45 Zucman-Rossi J, Legoix $P$, Sarkissian HD, Cheret G, Sor F, Bernardi A, Cazes L, Giraud S, Ollagnon E, Lenoir G, Thomas G. NF2 gene in neurofibromatosis type 2 patients. Hum Mol Genet 1998;7:2095-101.

46 Bruder CEG, Hirvela C, Tapia-Paez I, Fransson I, Segraves R, Hamilton G, Zhang XX, Evans DG, Wallace AJ, Baser ME, Zucman-Rossi J, Hergersberg $M$, Boltshauser E, Papi L, Rouleau GA, Poptodorov G, Jordanova A, RaskAndersen H, Kluwe L, Mautner V, Sainio M, Hung G, Mathiesen T, Moller C, Pulst SM, Harder H, Heiberg A, Honda M, Niimura M, Sahlen S, Blennow E, Albertson DG, Pinkel D, Dumanski JP. High resolution deletion analysis of constitutional DNA from neurofibromatosis type 2 (NF2) patients using microarray-CGH. Hum Mol Genet 2001;10:271-82.

47 Lopez-Correa C, Zucman-Rossi J, Brems H, Thomas G, Legius E. NF2 gene deletion in a family with a mild phenotype. J Med Genet 2000;37:75-7.

48 Bruder CEG, Ichimura K, Blenow E, Ikeuchi T, Yamaguchi T, Yuasa Y, Collins VP, Dumanski JP. Severe phenotype of the neurofibromatosis type 2 gene in patients with a $7.4 \mathrm{Mbp}$ constitutional deletion on chromosome 22 possible localization of a neurofibromatosis type 2 modifier gene, Genes Chromosomes Cancer 1999;25:184-90.

49 Kluwe L, Mautner VF, Heinrich B, Dezube R, Jacoby LB, Friedrich RE, MacCollin M. Molecular study of frequency of mosaicism in neurofibromatosis 2 patients with bilateral vestibular schwannomas. J Med Genet 2003;40:109-14

50 Moyhuddin A, Baser ME, Watson C, Purcell S, Ramsden RT, Heiberg A, Wallace AJ, Evans DGR. Somatic mosaicism in neurofibromatosis 2: prevalence and risk of disease transmission to offspring. J Med Genet 2003;40:459-63.

51 Baser ME, Friedman JM, Wallace AJ, Ramsden RT, Joe H, Evans DG. Evaluation of clinical diagnostic criteria for neurofibromatosis 2. Neurology 2002;59:1759-65

52 Zhao Y, Kumar RA, Baser ME, Evans DGR, Wallace A, Kluwe L, Mautner VF, Parry DM, Rouleau GA, Joe H, Friedman JM. Intrafamilial correlation of clinical manifestations in neurofibromatosis 2 (NF2). Genet Epidemiol 2002;23:245-59

53 Baser ME, Makariou EV, Parry DM. Predictors of vestibular schwannoma growth in patients with neurofibromatosis Type 2. J Neurosurg 2002; 96:217-22.

54 Baser ME, Ragge NK, Riccardi VM, Janus T, Gantz B, Pulst SM. Phenotypic variability in monozygotic twins with neurofibromatosis 2 . Am J Med Genet 1996;54:563-7. 